\title{
New data on activation cross section for deuteron induced reactions on ytterbium up to $50 \mathrm{MeV}$
}

\author{
F. Tárkányi ${ }^{\mathrm{a}}$, F. Ditrói ${ }^{\mathrm{a}, *}$, S. Takács ${ }^{\mathrm{a}}$, A. Hermanne ${ }^{\mathrm{b}}$, A.V. Ignatyuk ${ }^{\mathrm{c}}$ \\ ${ }^{a}$ Institute for Nuclear Research, Hungarian Academy of Sciences (ATOMKI), Debrecen, Hungary \\ ${ }^{b}$ Cyclotron Laboratory, Vrije Universiteit Brussel (VUB), Brussels, Belgium \\ ${ }^{c}$ Institute of Physics and Power Engineering (IPPE), Obninsk, Russia
}

\begin{abstract}
Activation cross sections of deuteron induced reactions on ytterbium for production of ${ }^{177 g, 173,172,171,170,169,167} \mathrm{Lu}$, ${ }^{177,175,169} \mathrm{Yb}$ and ${ }^{173,168,167,165} \mathrm{Tm}$ were extended up to $50 \mathrm{MeV}$ deuteron energy. The new data are in acceptable agreement with the earlier experimental data in the overlapping energy region. The experimental data are compared with the predictions of the ALICE-D, EMPIRE-D and TALYS 1.4 (TENDL-2013 on-line library results) codes.
\end{abstract}

Keywords: ytterbium target, deuteron activation, $\mathrm{Lu}, \mathrm{Yb}$ and $\mathrm{Tm}$ radioisotopes

\section{Introduction}

To meet the requirements of improving the reliability of available experimental and theoretical cross section data, we started to establish an experimental database some years ago, by performing new experiments and making a systematical survey of published deuteron induced activation cross-sections up to $50 \mathrm{MeV}$ [1]. In an earlier publication we presented the activation crosssections of longer-lived products of deuteron induced nuclear reactions on ytterbium up to $40 \mathrm{MeV}$, obtained in irradiations at the Sendai cyclotron [2]. The earlier data of Nichols et al. [3], Hermanne et al., [4], Manenti et al. [5] and Dmitriev et al. [6] were discussed in more detail at energies below $30 \mathrm{MeV}$ in this publication. Since that time only one new work was published by Manenti et al. on physical optimization of production of high specic activity ${ }^{177 g} \mathrm{Lu}$ by deuteron irradiation [7]. We have had now the possibility to extend the energy range up to $50 \mathrm{MeV}$ deuteron energy and to investigate some shorter-lived reaction products (in the $40 \mathrm{MeV}$ experiments the first $\gamma$-spectra could only be measured one day after end of bombardment). To avoid repetition of the content of our previous paper [2] we describe the experiment, the results and the theoretical comparisons only in summary form.

*Corresponding author: ditroi@atomki.hu

\section{Experiment and data evaluation}

For measurements, the well-known stacked foil irradiation technique and high resolution $\gamma$-spectrometry were used. $\mathrm{Yb}$ metal foils, interleaved with $\mathrm{Al}$ foils for monitoring beam characteristics were stacked and irradiated at the UCL (LLN) cyclotron. The Yb foils were irradiated together with $\mathrm{Nd}$ foils. The report on activation cross section data on $\mathrm{Nd}$ is in progress [8]. The main experimental parameters and methods of data evaluation are summarized in Table 1 . The complete excitation function was measured for the ${ }^{\text {nat }} \mathrm{Al}(\mathrm{d}, \mathrm{x})^{24} \mathrm{Na}$ monitor reactions, allowing to control the beam intensity and the energy by comparison with recommended data [9], and are shown in Fig. 1 in our earlier submitted paper on nuclear reactions on simultaneously irradiated $\mathrm{Nd}$ [7]. The decay characteristics of the investigated reaction products and the possibly contributing reactions in the energy region studied are summarized in Table 2. It should be mentioned that in a few cases we could not find independent $\gamma$-lines to assess the produced activity of the investigated radioisotopes. In these cases the contributions of the overlapping $\gamma$-lines from the decay of the other nuclides were subtracted.

\section{Comparison with the results of model codes}

In our previous work we made calculations for the investigated reactions using the modified model codes ALICE-IPPE [17] and EMPIRE-II [18]. In the used

September 4, 2018 
Table 1: Main experimental parameters and main parameters and methods of the data evaluation

\begin{tabular}{|c|c|c|c|}
\hline \multicolumn{2}{|l|}{ Main experimental parameters } & \multicolumn{2}{|l|}{ Methods of the data evaluation } \\
\hline Incident particle & Deuteron (LLN) & Gamma spectra evaluation & Genie $2000[10$, , Forgamma 11$]$ \\
\hline Method & Stacked foil & Determination of beam intensity & $\begin{array}{l}\text { Faraday cup (preliminary) } \\
\text { Fitted monitor reaction (final) [12 }\end{array}$ \\
\hline Target composition & 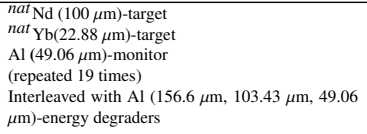 & Determination of beam intensity & $\begin{array}{l}\text { Faraday cup (preliminary) } \\
\text { Fitted monitor reaction (final) } 9.12\end{array}$ \\
\hline Number of Yb target foils & 19 & Decay data (see Table 2) & NUDAT 2.6 13 \\
\hline Accelerator & $\begin{array}{l}\text { Cyclone1 } 10 \text { cyclotron of Universit Catholique in } \\
\text { Louvain la Neuve (LLN) Belgium }\end{array}$ & Reaction Q-values(see Table 2) & Q-value calculator [14] \\
\hline Primary energy & $50 \mathrm{MeV}$ & Determination of beam energy & $\begin{array}{l}\text { Andersen (preliminary } 15 \\
\text { Fitted monitor reaction (final) } \\
9\end{array}$ \\
\hline Covered energy range & $48.2-12.9 \mathrm{MeV}$ & Uncertainty of energy & $\begin{array}{l}\text { Cumulative effects of possible uncertainties } \\
\text { (primary energy, target thickness, energy straggling, } \\
\text { correction to monitor reaction) }\end{array}$ \\
\hline Irradiation time & $60 \mathrm{~min}$ & Cross sections & Isotopic and elemental cross sections \\
\hline Beam current & $92 \mathrm{nA}$ & Uncertainty of cross sections & $\begin{array}{l}\text { Sum in quadrature of all individual contributions: } \\
\text { beam current }(7 \%), \text { beam-loss corrections (max. of } \\
1.5 \%) \text {, target thickness }(1 \%) \text {, } \\
\text { detector efficiency }(5 \%) \text {, } \\
\text { photo peak area determination and counting statistics } \\
(1-2016\end{array}$ \\
\hline Monitor reaction [recommended values] & $\begin{array}{l}{ }^{27} \mathrm{Al}(\mathrm{d}, \mathrm{x})^{24} \mathrm{Na} \text { reaction }[9 \\
\text { (re-measured over the whole energy range) }\end{array}$ & & \\
\hline Monitor target and thickness & Cityplacenat $\mathrm{Al}, 49.06 \mathrm{~mm}$ & & \\
\hline detector & HPGe & & \\
\hline Chemical separation & no & & \\
\hline$\gamma$-spectra measurements & 3 series & & \\
\hline $\begin{array}{l}\text { Cooling times } \\
\text { (and corresponding target-detector distances) }\end{array}$ & $\begin{array}{l}2.1-5.5 \mathrm{~h}(25 \mathrm{~cm}) \\
23.7-30.7 \mathrm{~h}(15 \mathrm{~cm}) \\
36.9-432.2 \mathrm{~h}(5 \mathrm{~cm})\end{array}$ & & \\
\hline
\end{tabular}

modified code versions ALICE-IPPE-D and EMPIRE$\mathrm{D}$, the direct $(\mathrm{d}, \mathrm{p})$ channel is increased strongly [19,20]. Here we repeat these results for comparison above 40 $\mathrm{MeV}$ too. The new experimental data are also compared with the cross section data reported in the TALYS 1.4 based [21] TENDL-2013 data libraries [22].

\section{Results}

The cross-sections for all reactions investigated are shown in Figs. 114 and the numerical values are shown in Tables 3-4. The contributing reactions can be found in Table 2. The reactions were discussed in detail in our previous work [2]. The agreement (or disagreement) of the new data with the previous experimental data and with the model results are shown in the corresponding figures and discussed below. The new results are in acceptable agreement with the previous data in most cases. As in [2] we deduced already integral yields for production of the investigated reaction products up to $40 \mathrm{MeV}$, we did not include in this paper a new figure extended to $50 \mathrm{MeV}$.

\section{1. ${ }^{177 g} \mathrm{Lu}$ (cum)}

The cumulative production of ${ }^{177 g} \mathrm{Lu}(6.71 \mathrm{~d}$ halflife) following the total decay of parent ${ }^{177} \mathrm{Yb}\left(\mathrm{T}_{1 / 2}=\right.$
$1.9 \mathrm{~h}$ ) was detected. It practically contains no contribution from the internal decay of ${ }^{177 m} \mathrm{Lu}(160.4 \mathrm{~d}$, IT 21.7\%) (long-lived, low formation cross-section). Only two cross section points were reliably assessed, near the maximum (Fig. 1). The new data are in good agreement with our earlier results, but somewhat higher than the results of Manenti [5] and Hermanne [4]. The nuclear model codes, especially the TENDL-2013 give lower values in this energy region.

\section{2. ${ }^{173} \mathrm{Lu}$}

The production of ${ }^{173} \mathrm{Lu}(1.37$ a) arises from ${ }^{n a t} \mathrm{Yb}(\mathrm{d}, \mathrm{xn})^{173} \mathrm{Lu}$ reactions on different stable $\mathrm{Yb}$ isotopes (Fig. 2). The new data are in good agreement with our earlier results [2] and also with those of Manenti [5] and Hermanne [4]. The values of Nichols [3] do not even reproduce the first maximum. The nuclear model codes follow the shape of the experimental curve and also the values, but it is difficult to judge, which of them gives the best approximation.

\section{3. ${ }^{172 g} \mathrm{Lu}(\mathrm{m+})$}

The cross sections contain the complete contribution of the decay of short-lived isomeric state (3.7 min) (Fig. 3). Our new data are in good agreement with the earlier experimental results. The best approximation is given by the TALYS (TENDL-2013) nuclear reaction model 


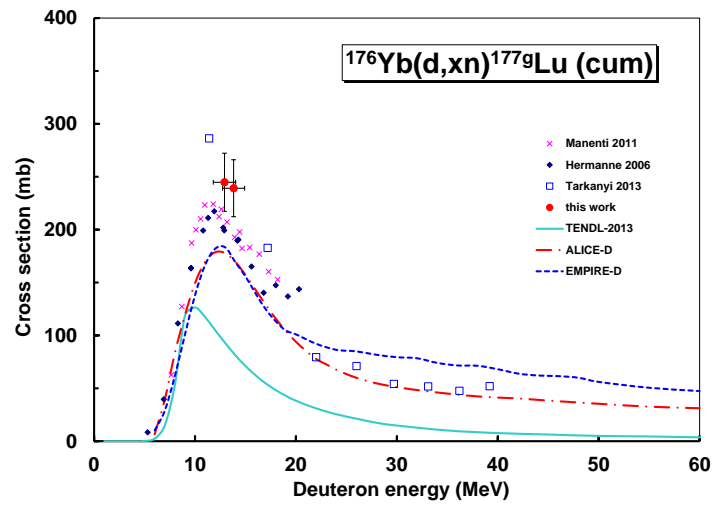

Figure 1: Excitation function of the ${ }^{176} \mathrm{Yb}(\mathrm{d}, \mathrm{x})^{177 g} \mathrm{Lu}$ reaction

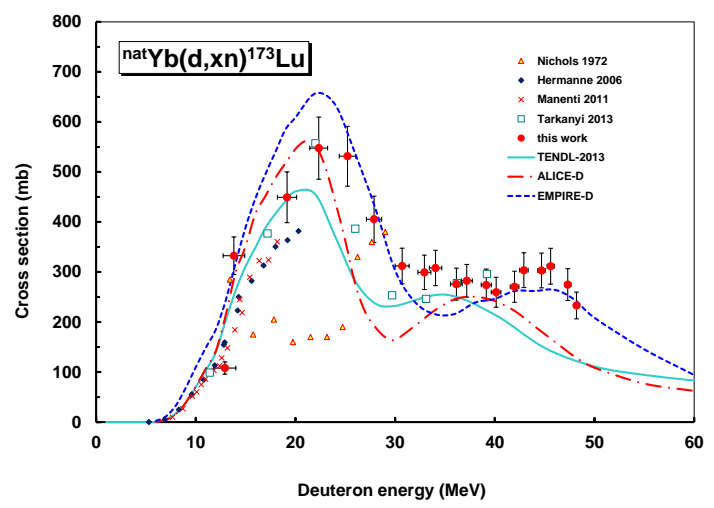

Figure 2: Excitation function of the ${ }^{\text {nat }} \mathrm{Yb}(\mathrm{d}, \mathrm{xn}){ }^{173} \mathrm{Lu}$ reaction

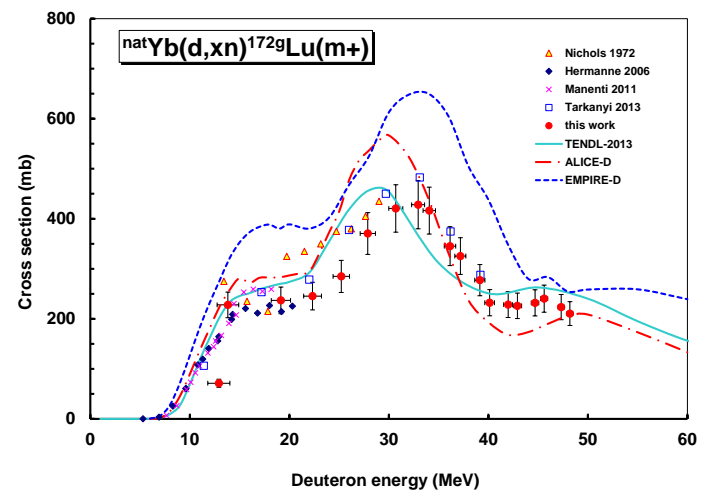

Figure 3: Excitation function of the ${ }^{\text {nat }} \mathrm{Yb}(\mathrm{d}, \mathrm{xn})^{172 \mathrm{mg}}$ Lu reaction

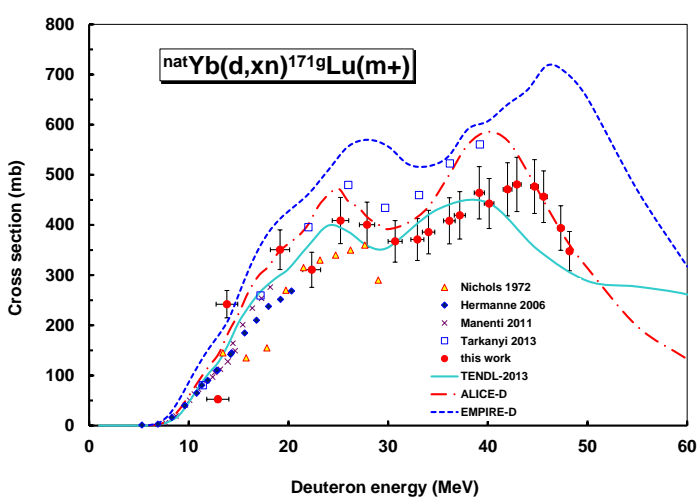

Figure 4: Excitation function of the ${ }^{\text {nat }} \mathrm{Yb}(\mathrm{d}, \mathrm{xn}){ }^{171 \mathrm{mg}} \mathrm{Lu}$ reaction

code, while both other codes overestimate the maximum and also the maximum energy.

\section{4. ${ }^{171 g} \mathrm{Lu}(m+)$}

The cumulative production of $171 \mathrm{Lu}(8.24 \mathrm{~d})$ includes the complete decay through isomeric transition of the short-lived (79 s) isomeric state (Fig. 4). The new data are in good agreement with our former results, with the experimental results of Hermanne [4] and Manenti [5], but give somewhat lower values than our previous results between 20 and $40 \mathrm{MeV}$. The best estimate is given by the TENDL-2013 prediction. 


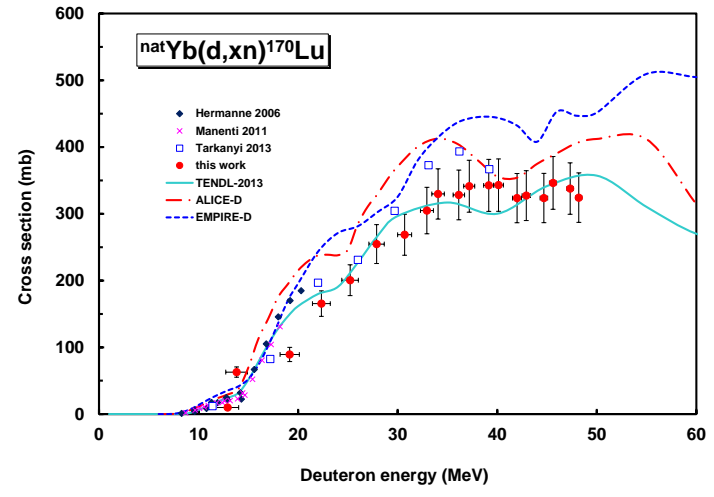

Figure 5: Excitation function of the ${ }^{\text {nat }} \mathrm{Yb}(\mathrm{d}, \mathrm{xn}){ }^{170} \mathrm{Lu}$ reaction

\section{5. ${ }^{170} \mathrm{Lu}$}

No parent contribution exists for the formation of ${ }^{170} \mathrm{Lu}$ (no isomeric state), so the presented results are direct cross-sections resulting from $(\mathrm{d}, \mathrm{xn})$ reactions (Fig. 5). Our new data are in good agreement with the previous experimental results, except the first local maximum, where our previous results were slightly higher. The best computational approximation is given by the TENDL-2013 library again.

\section{6. ${ }^{169} \mathrm{Lu}$}

${ }^{169} \mathrm{Lu}(32.018 \mathrm{~d})$ is produced directly via the ${ }^{n a t} \mathrm{Yb}(\mathrm{d}, \mathrm{xn})$ reactions (Fig. 6). The new data are in good agreement with our previous experimental results. The best model approach is given by the TENDL-2013 library again.

\section{7. ${ }^{167} \mathrm{Lu}$}

No earlier experimental data were found for the formation of ${ }^{167} \mathrm{Lu}$ through the ${ }^{\text {nat }} \mathrm{Yb}(\mathrm{d}, \mathrm{xn}){ }^{167} \mathrm{Lu}$ reactions. Our new data for production of ${ }^{167} \mathrm{Lu}(51.5 \mathrm{~min})$ are presented in Fig. 7. Our new experimental data are below all predictions of the nuclear reaction model codes.

\section{8. ${ }^{177} \mathrm{Yb}$}

In our previous measurement up to $40 \mathrm{MeV}$ [2] we could not identify the $\gamma$-lines of ${ }^{177} \mathrm{Yb}(1.911 \mathrm{~h})$ in our spectra due to the long cooling time. As in these experiments measurements could be started $2 \mathrm{~h}$ after EOB, a statistically significant signal for the independent 150.3 $\mathrm{keV}$ line of ${ }^{177} \mathrm{Yb}$ could be identified. The new results are shown in Fig. 8, and are in good agreement

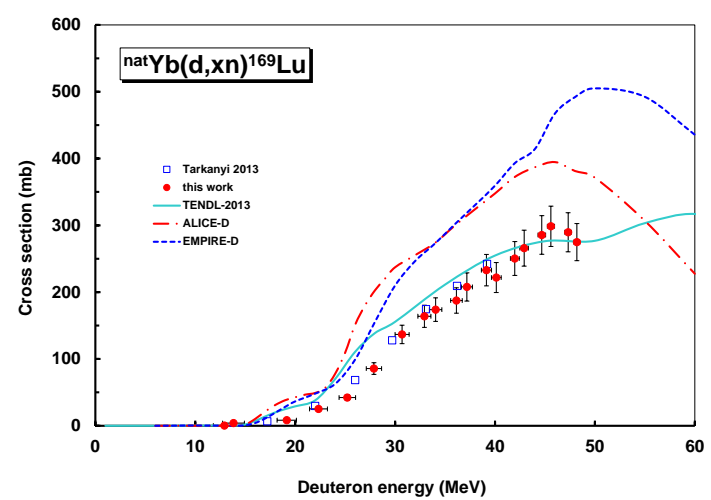

Figure 6: Excitation function of the ${ }^{\text {nat }} \mathrm{Yb}(\mathrm{d}, \mathrm{xn}){ }^{169}$ Lu reaction

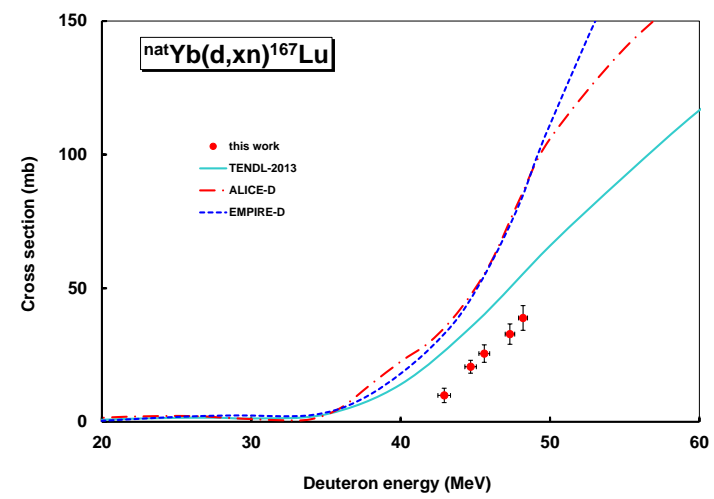

Figure 7: Excitation function of the ${ }^{\text {nat }} \mathrm{Yb}(\mathrm{d}, \mathrm{xn}){ }^{167} \mathrm{Lu}$ reaction 


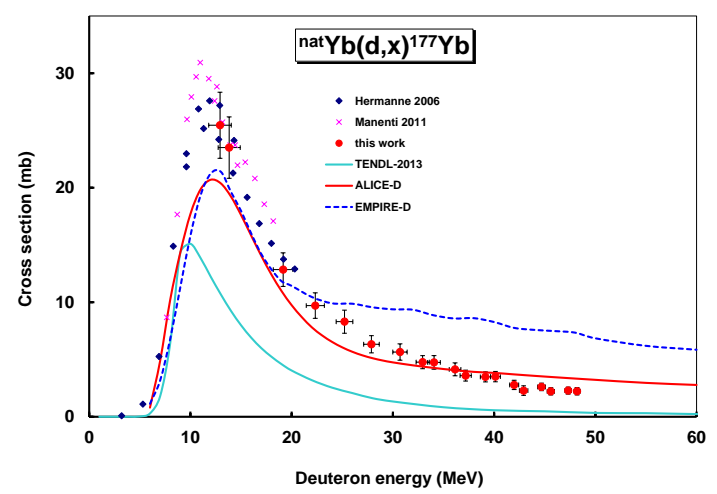

Figure 8: Excitation function of the ${ }^{176} \mathrm{Yb}(\mathrm{d}, \mathrm{p})^{177} \mathrm{Yb}$ reaction

with [4] and [5]. ${ }^{177} \mathrm{Yb}$ can only be produced via the ${ }^{176} \mathrm{Yb}(\mathrm{d}, \mathrm{p}){ }^{177} \mathrm{Yb}$ reaction. All nuclear reaction model codes underestimate the maximum value, the best estimate is given by the ALICE-D code (due to its improved (d,p) capability).

\section{9. ${ }^{175} \mathrm{Yb}(\mathrm{cum})$}

The cumulative production of ${ }^{175} \mathrm{Yb}(4.185 \mathrm{~d})$ (via direct (d,pxn) reactions and from $\beta^{-}$-decay of ${ }^{175} \mathrm{Tm}(15.2$ $\min )$ ) is shown in Fig. 9. Our new data support the earlier data from our group $[2,5]$ in the lower energy region due to the ${ }^{176} \mathrm{Yb}(\mathrm{d}, 2 \mathrm{pn})$ reaction. All nuclear reaction codes underestimate the experimental values, only the first maximum energy is given correctly by the ALICE$\mathrm{D}$ and EMPIRE-D codes. The second broad maximum is only predicted by the TENDL-2013 library.

\subsection{0. ${ }^{169} \mathrm{Yb}$ (cum)}

The measured cumulative activation cross-sections of ${ }^{169} \mathrm{Yb}\left(\mathrm{T}_{1 / 2}=32.018 \mathrm{~d}\right)$ are shown in Fig. 10. This radioisotope is obtained through direct production via ${ }^{\text {nat }} \mathrm{Yb}(\mathrm{d}, \mathrm{pxn})$ reactions and from the decay of the shorter-lived parent ${ }^{169} \mathrm{Lu}(34.06 \mathrm{~h})$. Our new data are in good agreement with our previous results in the overlapping energy range and also with the other experiment in the low energy region. Now, all the nuclear reaction model codes give similar results in the measured energy region. The TENDL-2013 prediction seems to be the closest approximation, but it does not predict the expected maximum below $50 \mathrm{MeV}$.

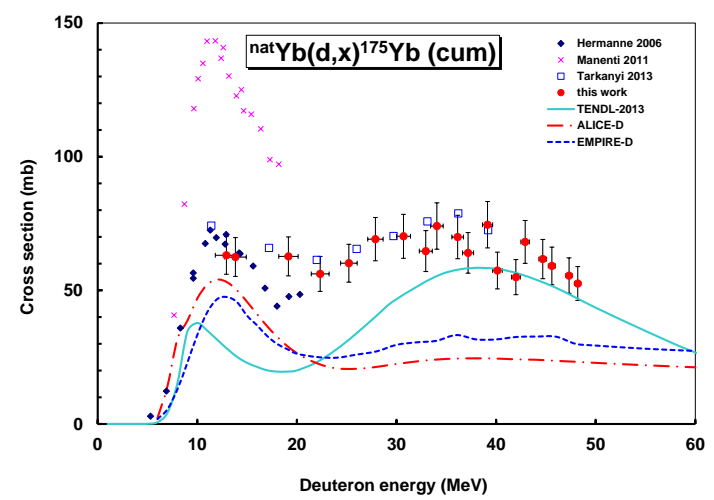

Figure 9: Excitation function of the ${ }^{\text {nat }} \mathrm{Yb}(\mathrm{d}, \mathrm{x})^{175} \mathrm{Yb}$ process

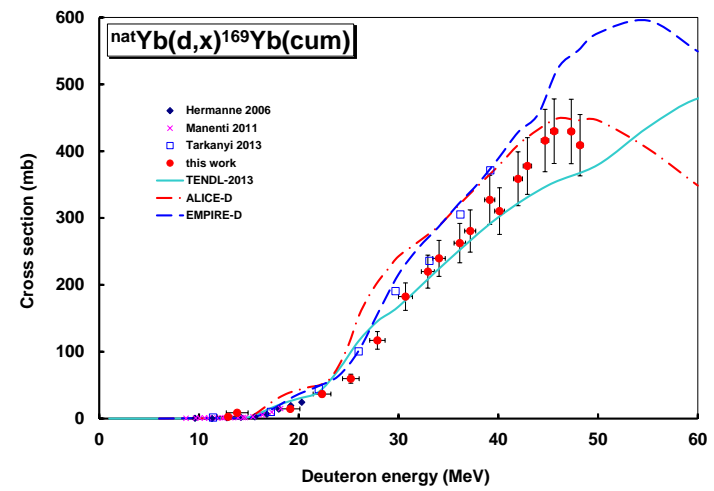

Figure 10: Excitation function of the ${ }^{\text {nat }} \mathrm{Yb}(\mathrm{d}, \mathrm{x}){ }^{169} \mathrm{Yb}$ reaction 


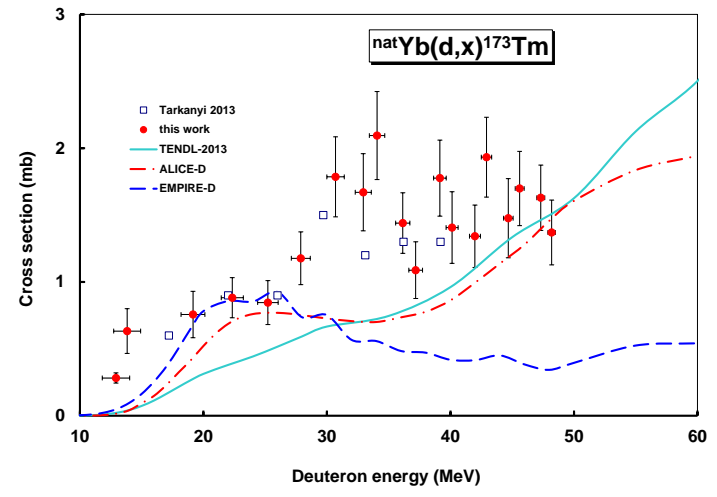

Figure 11: Excitation function of the ${ }^{\text {nat }} \mathrm{Yb}(\mathrm{d}, \mathrm{x})^{173} \mathrm{Tm}$ reaction

\subsection{1. ${ }^{173} \mathrm{Tm}$}

The cross sections of directly produced ${ }^{173} \mathrm{Tm}(8.24$ h) are presented on Fig. 11. In spite of the quite strong scattering, our new experimental data support our previous measurement. EMPIRE-D and ALICE-D give acceptable estimates below $27 \mathrm{MeV}$, reproducing the first local maximum too, while TALYS completely fails in this case.

\subsection{2. ${ }^{168} \mathrm{Tm}$}

The measured excitation function for direct production of ${ }^{168} \mathrm{Tm}$ (93.1 d) is shown in Fig. 12. Because of the low statistics the data are scattered again, but the good agreement with our previous results is obvious. All nuclear reaction model codes, especially TALYS, underestimate the experimental values.

\subsection{3. ${ }^{167} \mathrm{Tm}$ (cum)}

The excitation function for cumulative production of ${ }^{167} \mathrm{Tm}(9.25 \mathrm{~d})$ (direct reactions and from the decay of short-lived parent ${ }^{167} \mathrm{Yb}(17.5 \mathrm{~min})$ ) are sown in Fig. 13. The best prediction is provided by the TENDL-2013 library above $35 \mathrm{MeV}$, while under $35 \mathrm{MeV}$ all the three codes show approximately the same results.

\subsection{4. ${ }^{165} \mathrm{Tm}$ (cum)}

The measured excitation function for ${ }^{165} \mathrm{Tm}$ (30.06 h) is shown in Fig. 14. It was produced both directly through ${ }^{\text {nat }} \mathrm{Yb}(\mathrm{d}, \mathrm{pxn})$ reactions and indirectly from decay of short-lived parent ${ }^{165} \mathrm{Yb}$ (9.9 min). The overlap with our previous results is acceptable. The best prediction is given by the ALICE-D code in this case.

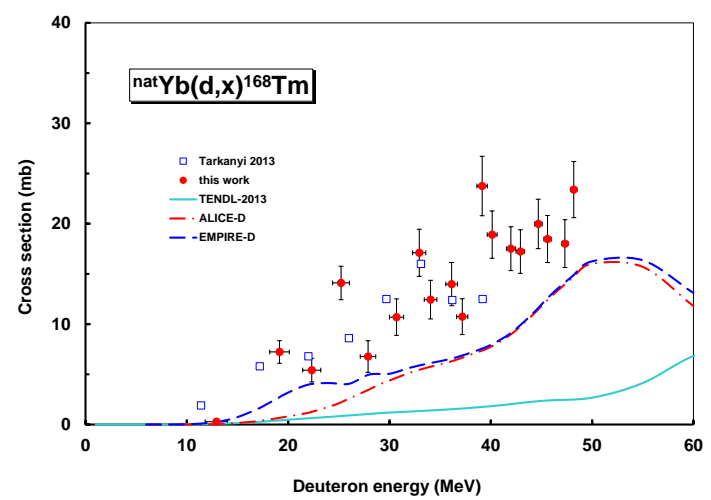

Figure 12: Excitation function of the ${ }^{\text {nat }} \mathrm{Yb}(\mathrm{d}, \mathrm{x})^{168} \mathrm{Tm}$ reaction

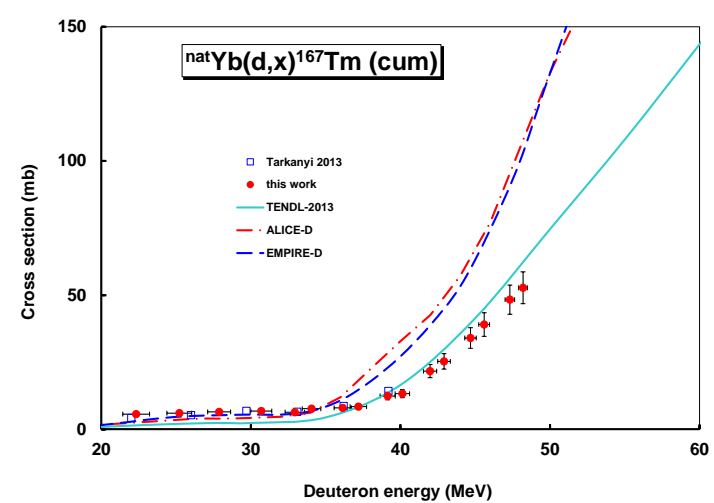

Figure 13: Excitation function of the ${ }^{n a t} \mathrm{Yb}(\mathrm{d}, \mathrm{x})^{167} \mathrm{Tm}$ reaction 


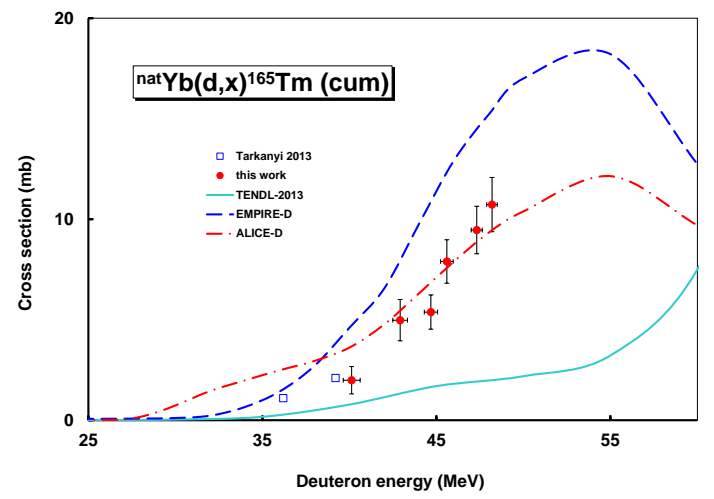

Figure 14: Excitation function of the ${ }^{\text {nat }} \mathrm{Yb}(\mathrm{d}, \mathrm{x})^{165} \mathrm{Tm}$ reaction

\section{Summary and conclusion}

Excitation functions of deuteron induced nuclear reactions on natural $\mathrm{Yb}$ were measured up to $50 \mathrm{MeV}$, as an extension and improvement of our earlier works. The comparison with the earlier experimental data, measured at lower energies, shows acceptable agreement (except for ${ }^{173} \mathrm{Lu}$ and ${ }^{175} \mathrm{Yb}$ ). The experimental data were compared with the results of our ALICE-D and EMPIRE-D calculations and with the data in the TENDL-2013 library based on TALYS 1.4 calculations. The theoretical descriptions of the experimental excitation functions in shape and in absolute values are acceptable if we consider the large disagreements of the earlier versions of the used model codes. The obtained experimental data provide a basis for improved model calculations and for applications in different fields of nuclear medicine (e.g. cancer treatment), as tracer in nuclear biology, in industry and for non-destructive testing and as radioactive tracers in different processes (for related references see our earlier work [2]).

\section{Acknowledgements}

This work was performed in the frame of the HASFWO Vlaanderen (Hungary-Belgium) project. The authors acknowledge the support of the research project and of the respective institutions in providing the beam time and experimental facilities.

\section{Correction}

During the EXFOR compilation of our previous paper on cross sections for deuteron induced processes on $\mathrm{Yb}$ (F. Tarkanyi et al., Nucl. Instrum. Meth. section B,
304(2013)36-48 [2]) it was discovered that the decay data of ${ }^{169} \mathrm{Lu}$ are misprinted in Table 1 of that publication. However, the cross section values presented in the tables and in the figures are correct. The ${ }^{169} \mathrm{Yb}$ decay data used in the calculations are: $\mathrm{T}_{1 / 2}-34.04 \mathrm{~h}, \mathrm{E}_{\gamma}\left(\mathrm{I}_{\gamma}\right)$ $191.214 \mathrm{keV}(20.6 \%)$ and $960.622 \mathrm{keV}(23.4 \%)$.

\section{References}

[1] F. Tárkányi, A. Hermanne, F. Ditrói, S. Takács, B. Király, G. Csikai, M. Baba, H. Yamazaki, M. S. Uddin, A. V. Ignatyuk, S. M. Qaim, Systematic study of activation cross-sections of deuteron induced reactions used in accelerator applications (2528 Oct., 2010 2011).

[2] F. Tárkányi, F. Ditrói, S. Takács, A. Hermanne, H. Yamazaki, M. Baba, A. Mohammadi, A. V. Ignatyuk, Activation crosssections of longer lived products of deuteron induced nuclear reactions on ytterbium up to $40 \mathrm{mev}$, Nuclear Instruments and Methods in Physics Research B 304 (2013) 36-48.

[3] A. L. Nichols, R. J. Bullock, P. Glentworth, N. R. Large, Excitation functions for the formation of various gadolinium and lutetium isotopes by $(\mathrm{d}, \mathrm{xn})$ reactions, Tech. rep., Atomic Energy Research Establishment, Harwell (England) (1972).

[4] A. Hermanne, S. Takacs, M. B. Goldberg, E. Lavie, Y. N. Shubin, S. Kovalev, Deuteron-induced reactions on yb: Measured cross sections and rationale for production pathways of carrierfree, medically relevant radionuclides, Nuclear Instruments and Methods in Physics Research Section B: Beam Interactions with Materials and Atoms 247 (2) (2006) 223-231.

[5] S. Manenti, F. Groppi, A. Gandini, L. Gini, K. Abbas, U. Holzwarth, F. Simonelli, M. Bonardi, Excitation function for deuteron induced nuclear reactions on natural ytterbium for production of high specific activity lu- $177 \mathrm{~g}$ in no-carrier-added form for metabolic radiotherapy, Applied Radiation and Isotopes 69 (1) (2011) 37-45.

[6] P. P. Dmitriev, N. N. Krasnov, G. A. Molin, Radioactive nuclide yields for thick target at 22 mev deuterons energy, Yadernie Konstanti 34 (4) (1982) 38.

[7] S. Manenti, M. L. Bonardi, L. Gini, F. Groppi, Physical optimization of production by deuteron irradiation of high specific activity $177 \mathrm{glu}$ suitable for radioimmunotherapy, Nuclear Medicine and Biology in print (0).

[8] F. Tárkányi, S. Takács, F. Ditrói, A. Hermanne, H. Yamazaki, M. Baba, A. Mohammadi, A. V. Ignatyuk, Activation crosssections of deuteron induced nuclear reactions on neodymium up to $50 \mathrm{mev}$, Nuclear Instruments and Methods in Physics Research Section B: Beam Interactions with Materials and Atoms 325 (0) (2014) 15-26.

[9] F. Tárkányi, S. Takács, K. Gul, A. Hermanne, M. G. Mustafa, M. Nortier, P. Oblozinsky, S. M. Qaim, B. Scholten, Y. N. Shubin, Z. Youxiang, Beam monitor reactions (chapter 4). charged particle cross-section database for medical radioisotope production: diagnostic radioisotopes and monitor reactions., Tech. rep., IAEA (2001).

[10] Canberra, http://www.canberra.com/products/radiochemistry_lab/genie-2000-software.asp. (2000).

[11] G. Székely, Fgm - a flexible gamma-spectrum analysis program for a small computer, Computer Physics Communications 34 (3) (1985) 313-324.

[12] F. Tárkányi, F. Szelecsényi, S. Takács, Determination of effective bombarding energies and fluxes using improved stacked-foil technique, Acta Radiologica, Supplementum 376 (1991) 72. 
[13] NuDat, Nudat2 database (2.6) http://www.nndc.bnl.gov/nudat2/ (2014).

[14] B. Pritychenko, A. Sonzogni, Q-value calculator, http://www.nndc.bnl.gov/qcalc (2003).

[15] H. H. Andersen, J. F. Ziegler, Hydrogen stopping powers and ranges in all elements. The stopping and ranges of ions in matter, Volume 3., The Stopping and ranges of ions in matter, Pergamon Press, New York, 1977.

[16] I.-B. of-Weights-and Measures, Guide to the expression of uncertainty in measurement, 1st Edition, International Organization for Standardization, Genve, Switzerland, 1993.

[17] A. I. Dityuk, A. Y. Konobeyev, V. P. Lunev, Y. N. Shubin, New version of the advanced computer code alice-ippe, Tech. rep., IAEA (1998).

[18] M. Herman, R. Capote, B. V. Carlson, P. Oblozinsky, M. Sin, A. Trkov, H. Wienke, V. Zerkin, Empire: Nuclear reaction model code system for data evaluation, Nuclear Data Sheets 108 (12) (2007) 2655-2715.

[19] F. Tárkányi, A. Hermanne, S. Takács, F. Ditrói, I. Spahn, S. F. Kovalev, A. V. Ignatyuk, S. M. Qaim, Activation cross sections of the tm-169(d,2n) reaction for production of the therapeutic radionuclide yb-169, Applied Radiation and Isotopes 65 (6) (2007) 663-668.

[20] F. Tárkányi, A. Hermanne, S. Takács, K. Hilgers, S. F. Kovalev, A. V. Ignatyuk, S. M. Qaim, Study of the $1920 \mathrm{os}(\mathrm{d}, 2 \mathrm{n})$ reaction for, production of the therapeutic radionuclide 192ir in no-carrier added form, Applied Radiation and Isotopes 65 (11) (2007) 1215-1220.

[21] A. J. Koning, S. Hilaire, M. C. Duijvestijn, Talys-1.0 (2007).

[22] A. J. Koning, D. Rochman, S. van der Marck, J. Kopecky, J. C. Sublet, S. Pomp, H. Sjostrand, R. Forrest, E. Bauge, H. Henriksson, O. Cabellos, S. Goriely, J. Leppanen, H. Leeb, A. Plompen, R. Mills, Tendl-2013: Talys-based evaluated nuclear data library (2012) 
Table 2: Decay characteristics of the investigated reaction products and the contributing reactions

\begin{tabular}{|c|c|c|c|c|c|}
\hline Nuclide & Half-life & $\mathrm{E}_{\gamma}(\mathrm{keV})$ & $\mathrm{I}_{\gamma}(\%)$ & $\begin{array}{l}\text { Contributing } \\
\text { reaction }\end{array}$ & $\begin{array}{l}\text { Q-value } \\
\text { (MeV) }\end{array}$ \\
\hline $\begin{array}{l}{ }^{177 g} \mathrm{Lu} \\
\varepsilon: 100 \%\end{array}$ & $6.647 \mathrm{~d}$ & $\begin{array}{l}112.9498 \\
208.3662\end{array}$ & $\begin{array}{l}6.17 \\
10.36\end{array}$ & $\begin{array}{l}176 \mathrm{Yb}(\mathrm{d}, \mathrm{n}) \\
177 \mathrm{Yb} \text { decay }\end{array}$ & 3.9 \\
\hline $\begin{array}{l}{ }^{173} \mathrm{Lu} \\
\varepsilon: 100 \%\end{array}$ & $1.37 \mathrm{a}$ & $\begin{array}{l}78.63 \\
100.724 \\
272.105\end{array}$ & $\begin{array}{l}11.9 \\
5.24 \\
21.2\end{array}$ & $\begin{array}{l}172 \mathrm{Yb}(\mathrm{d}, \mathrm{n}) \\
{ }^{173} \mathrm{Yb}(\mathrm{d}, 2 \mathrm{n}) \\
{ }^{174} \mathrm{Yb}(\mathrm{d}, 3 \mathrm{n}) \\
176 \mathrm{Yb}(\mathrm{d}, 5 \mathrm{n})\end{array}$ & $\begin{array}{l}2.7 \\
-3.7 \\
-11.1 \\
-23.9\end{array}$ \\
\hline $\begin{array}{l}{ }^{172 g} \mathrm{Lu} \\
\varepsilon: 100 \%\end{array}$ & $6.70 \mathrm{~d}$ & $\begin{array}{l}78.7426 \\
181.525 \\
810.064 \\
900.724 \\
912.079 \\
1093.63\end{array}$ & $\begin{array}{l}10.6 \\
20.6 \\
16.6 \\
29.8 \\
15.3 \\
63\end{array}$ & $\begin{array}{l}171 \mathrm{Yb}(\mathrm{d}, \mathrm{n}) \\
172 \mathrm{Yb}(\mathrm{d}, 2 \mathrm{n}) \\
173 \mathrm{Yb}(\mathrm{d}, 3 \mathrm{n}) \\
174 \mathrm{Yb}(\mathrm{d}, 4 \mathrm{n}) \\
{ }^{176} \mathrm{Yb}(\mathrm{d}, 6 \mathrm{n})\end{array}$ & $\begin{array}{l}2.5 \\
-5.5 \\
-11.9 \\
-19.4 \\
-32.0\end{array}$ \\
\hline $\begin{array}{l}171 g_{\mathrm{Lu}} \\
\varepsilon: 100 \%\end{array}$ & $8.24 \mathrm{~d}$ & $\begin{array}{l}667.422 \\
739.793 \\
780.711 \\
839.961\end{array}$ & $\begin{array}{l}11.1 \\
47.9 \\
4.37 \\
3.05\end{array}$ & $\begin{array}{l}170 \mathrm{Yb}(\mathrm{d}, \mathrm{n}) \\
{ }^{171} \mathrm{Yb}(\mathrm{d}, 2 \mathrm{n}) \\
{ }^{172} \mathrm{Yb}(\mathrm{d}, 3 \mathrm{n}) \\
{ }^{173} \mathrm{Yb}(\mathrm{d}, 4 \mathrm{n}) \\
{ }^{174} \mathrm{Yb}(\mathrm{d}, 5 \mathrm{n}) \\
{ }^{176} \mathrm{Yb}(\mathrm{d}, 7 \mathrm{n})\end{array}$ & $\begin{array}{l}2.1 \\
-4.5 \\
-12.5 \\
-18.9 \\
-26.3 \\
-39.0\end{array}$ \\
\hline $\begin{array}{l}170 \mathrm{Lu} \\
\varepsilon: 100 \%\end{array}$ & $2.012 \mathrm{~d}$ & $\begin{array}{l}84.262 \\
193.13 \\
572.20 \\
985.10 \\
1054.28 \\
1138.65 \\
1280.25 \\
1341.20 \\
1364.60\end{array}$ & $\begin{array}{l}8.7 \\
2.07 \\
1.25 \\
5.4 \\
4.60 \\
3.49 \\
7.9 \\
3.15 \\
4.47\end{array}$ & $\begin{array}{l}170 \mathrm{Yb}(\mathrm{d}, 2 \mathrm{n}) \\
{ }^{171} \mathrm{Yb}(\mathrm{d}, 3 \mathrm{n}) \\
{ }^{172} \mathrm{Yb}(\mathrm{d}, 4 \mathrm{n}) \\
{ }^{173} \mathrm{Yb}(\mathrm{d}, 5 \mathrm{n}) \\
{ }^{174} \mathrm{Yb}(\mathrm{d}, 6 \mathrm{n}) \\
{ }^{176} \mathrm{Yb}(\mathrm{d}, 8 \mathrm{n})\end{array}$ & $\begin{array}{l}-6.5 \\
-13.1 \\
-21.1 \\
-27.5 \\
-34.9 \\
-47.6\end{array}$ \\
\hline $\begin{array}{l}{ }^{169} \mathrm{Lu} \\
\varepsilon: 100 \%\end{array}$ & $34.06 \mathrm{~h}$ & $\begin{array}{l}191.217 \\
960.622\end{array}$ & $\begin{array}{l}18.7 \\
21.2\end{array}$ & $\begin{array}{l}168 \mathrm{Yb}(\mathrm{d}, \mathrm{n}) \\
170 \mathrm{Yb}(\mathrm{d}, 3 \mathrm{n}) \\
171 \mathrm{Yb}(\mathrm{d}, 4 \mathrm{n}) \\
172 \mathrm{Yb}(\mathrm{d}, 5 \mathrm{n}) \\
173 \mathrm{Yb}(\mathrm{d}, 6 \mathrm{n}) \\
174 \mathrm{Yb}(\mathrm{d}, 7 \mathrm{n}) \\
176 \mathrm{Yb}(\mathrm{d}, 9 \mathrm{n})\end{array}$ & $\begin{array}{l}1.6 \\
-13.8 \\
-20.4 \\
-28.4 \\
-34.8 \\
-42.2 \\
-54 .\end{array}$ \\
\hline $\begin{array}{l}167 \mathrm{Lu} \\
\varepsilon: 100 \%\end{array}$ & $51.5 \mathrm{~min}$ & $\begin{array}{l}178.87 \\
213.20 \\
239.22 \\
401.17 \\
1267.26\end{array}$ & $\begin{array}{l}2.5 \\
3.33 \\
7.7 \\
3.17 \\
3.87\end{array}$ & $\begin{array}{l}168 \mathrm{Yb}(\mathrm{d}, 3 \mathrm{n}) \\
170 \mathrm{Yb}(\mathrm{d}, 5 \mathrm{n}) \\
171 \mathrm{Yb}(\mathrm{d}, 6 \mathrm{n}) \\
{ }^{172} \mathrm{Yb}(\mathrm{d}, 7 \mathrm{n}) \\
{ }^{173} \mathrm{Yb}(\mathrm{d}, 8 \mathrm{n}) \\
174 \mathrm{Yb}(\mathrm{d}, 9 \mathrm{n}) \\
176 \mathrm{Yb}(\mathrm{d}, 11 \mathrm{n})\end{array}$ & $\begin{array}{l}-15.2 \\
-30.5 \\
-37.1 \\
-45.1 \\
-51.5 \\
-59.0\end{array}$ \\
\hline $\begin{array}{l}177 \mathrm{Yb} \\
\beta^{-}: 100 \%\end{array}$ & $1.911 \mathrm{~h}$ & 150.3 & 20.5 & ${ }^{176} \mathrm{Yb}(\mathrm{d}, \mathrm{p})$ & 3.3 \\
\hline $\begin{array}{l}175 \mathrm{Yb} \\
\beta^{-}: 100 \%\end{array}$ & $4.185 \mathrm{~d}$ & $\begin{array}{l}113.805 \\
282.522 \\
396.329\end{array}$ & $\begin{array}{l}3.87 \\
6.13 \\
13.2\end{array}$ & $\begin{array}{l}174 \mathrm{Yb}(\mathrm{d}, \mathrm{p}) \\
{ }^{176} \mathrm{Yb}(\mathrm{d}, \mathrm{p} 2 \mathrm{n}) \\
{ }^{175} \mathrm{Tm} \text { decay }\end{array}$ & $\begin{array}{l}3.6 \\
-9.1\end{array}$ \\
\hline $\begin{array}{l}{ }^{169} \mathrm{Yb} \\
\varepsilon: 100 \%\end{array}$ & $32.018 \mathrm{~d}$ & $\begin{array}{l}109.77924 \\
130.52293 \\
177.21307 \\
197.95675 \\
307.52 \\
307.73586\end{array}$ & $\begin{array}{l}17.39 \\
11.38 \\
22.28 \\
35.93 \\
0.3 \\
10.05\end{array}$ & $\begin{array}{l}168 \mathrm{Yb}(\mathrm{d}, \mathrm{p}) \\
{ }^{170} \mathrm{Yb}(\mathrm{d}, \mathrm{p} 2 \mathrm{n}) \\
{ }^{171} \mathrm{Yb}(\mathrm{d}, \mathrm{p} 3 \mathrm{n}) \\
{ }^{172} \mathrm{Yb}(\mathrm{d}, \mathrm{p} 4 \mathrm{n}) \\
{ }^{173} \mathrm{Yb}(\mathrm{d}, \mathrm{p} 5 \mathrm{n}) \\
{ }^{174} \mathrm{Yb}(\mathrm{d}, \mathrm{p} 6 \mathrm{n}) \\
{ }^{176} \mathrm{Yb}(\mathrm{d}, \mathrm{p} 8 \mathrm{n}) \\
{ }^{169} \mathrm{Lu} \text { decay }\end{array}$ & $\begin{array}{l}4.6 \\
-10.7 \\
-17.3 \\
-25.3 \\
-31.7 \\
-39.2 \\
-51.9\end{array}$ \\
\hline $\begin{array}{l}173 \mathrm{Tm} \\
\beta^{-}: 100 \%\end{array}$ & $8.24 \mathrm{~h}$ & $\begin{array}{l}398.9 \\
461.4\end{array}$ & $\begin{array}{l}87.9 \\
6.9\end{array}$ & $\begin{array}{l}173 \mathrm{Yb}(\mathrm{d}, 2 \mathrm{p}) \\
{ }^{174} \mathrm{Yb}(\mathrm{d}, 2 \mathrm{pn}) \\
176 \mathrm{Yb}(\mathrm{d}, 2 \mathrm{p} 3 \mathrm{n})\end{array}$ & $\begin{array}{l}-2.7 \\
-10.2 \\
-22.9\end{array}$ \\
\hline $\begin{array}{l}{ }^{172} \mathrm{Tm} \\
\beta^{-}: 100 \%\end{array}$ & $63.6 \mathrm{~h}$ & $\begin{array}{l}78.750 \\
181.520 \\
1093.59 \\
1387.093\end{array}$ & $\begin{array}{l}6.5 \\
2.8 \\
6.0 \\
5.6\end{array}$ & $\begin{array}{l}172 \mathrm{Yb}(\mathrm{d}, 2 \mathrm{p}) \\
173 \mathrm{Yb}(\mathrm{d}, 2 \mathrm{pn}) \\
174 \mathrm{Yb}(\mathrm{p}, 2 \mathrm{p} 2 \mathrm{n}) \\
{ }^{176} \mathrm{Yb}(\mathrm{p}, 2 \mathrm{p} 4 \mathrm{n})\end{array}$ & $\begin{array}{l}-3.3 \\
-9.7 \\
-17.2 \\
-29.8\end{array}$ \\
\hline $\begin{array}{l}{ }^{168} \mathrm{Tm} \\
\varepsilon: \\
99.99 \% \\
\beta^{-}: \\
0.01 \%\end{array}$ & $93.1 \mathrm{~d}$ & $\begin{array}{l}79.804 \\
184.295 \\
198.251 \\
447.515 \\
720.392 \\
741.355 \\
815.989 \\
821.162\end{array}$ & \begin{tabular}{l|l|}
10.95 \\
18.55 \\
54.49 \\
23.98 \\
12.207 \\
12.81 \\
50.95 \\
11.99
\end{tabular} & $\begin{array}{l}168 \mathrm{Yb}(\mathrm{d}, 2 \mathrm{p}) \\
{ }^{170} \mathrm{Yb}(\mathrm{d}, 2 \mathrm{p} 2 \mathrm{n}) \\
171 \mathrm{Yb}(\mathrm{d}, 2 \mathrm{p} 3 \mathrm{n}) \\
172 \mathrm{Yb}(\mathrm{d}, 2 \mathrm{p} 4 \mathrm{n}) \\
{ }^{173} \mathrm{Yb}(\mathrm{d}, 2 \mathrm{p} 5 \mathrm{n}) \\
{ }^{174} \mathrm{Yb}(\mathrm{d}, 2 \mathrm{p} 6 \mathrm{n}) \\
{ }^{176} \mathrm{Yb}(\mathrm{d}, 2 \mathrm{p} 8 \mathrm{n})\end{array}$ & $\begin{array}{l}-1.7 \\
-17.0 \\
-23.7 \\
-31.7 \\
-38.0 \\
-45.5 \\
-58.2\end{array}$ \\
\hline $\begin{array}{l}{ }^{167} \mathrm{Tm} \\
\varepsilon: 100 \%\end{array}$ & $9.25 \mathrm{~d}$ & $\begin{array}{l}207.801 \\
531.54\end{array}$ & $\begin{array}{l}42 \\
1.61\end{array}$ & $\begin{array}{l}168 \mathrm{Yb}(\mathrm{d}, 2 \mathrm{pn}) \\
{ }^{170} \mathrm{Yb}(\mathrm{d}, 2 \mathrm{p} 3 \mathrm{n}) \\
{ }^{171} \mathrm{Yb}(\mathrm{d}, 2 \mathrm{p} 4 \mathrm{n}) \\
{ }^{172} \mathrm{Yb}(\mathrm{d}, 2 \mathrm{p} 5 \mathrm{n}) \\
{ }^{173} \mathrm{Yb}(\mathrm{d}, 2 \mathrm{p} 6 \mathrm{n}) \\
{ }^{174} \mathrm{Yb}(\mathrm{d}, 2 \mathrm{p} 7 \mathrm{n}) \\
176 \mathrm{Yb}(\mathrm{d}, 2 \mathrm{p} 9 \mathrm{n}) \\
{ }^{167} \mathrm{Yb} \text { decay }\end{array}$ & $\begin{array}{l}-8.5 \\
-23.9 \\
-30.5 \\
-38.5 \\
-44.9 \\
-52.3 \\
-65.0\end{array}$ \\
\hline $\begin{array}{l}{ }^{165} \mathrm{Tm} \\
\varepsilon: 100 \%\end{array}$ & $30.06 \mathrm{~h}$ & $\begin{array}{l}242.917 \\
296.49 \\
297.369 \\
460.263\end{array}$ & $\begin{array}{l}35.5 \\
3.88 \\
12.7 \\
4.12\end{array}$ & $\begin{array}{l}168 \mathrm{Yb}(\mathrm{d}, 2 \mathrm{p} 3 \mathrm{n}) \\
170 \mathrm{Yb}(\mathrm{d}, 2 \mathrm{p} 5 \mathrm{n}) \\
171 \mathrm{Yb}(\mathrm{d}, 2 \mathrm{p} 6 \mathrm{n}) \\
172 \mathrm{Yb}(\mathrm{d}, 2 \mathrm{p} 7 \mathrm{n}) \\
173 \mathrm{Yb}(\mathrm{d}, 2 \mathrm{p} 8 \mathrm{n}) \\
174 \mathrm{Yb}(\mathrm{d}, 2 \mathrm{p} 9 \mathrm{n}) \\
176 \mathrm{Yb}(\mathrm{d}, 2 \mathrm{p} 11 \mathrm{n}) \\
1{ }^{165} \mathrm{Yb} \text { decay }\end{array}$ & $\begin{array}{l}-24.3 \\
-39.6 \\
-46.2 \\
-54.3 \\
-60.6 \\
-68.1\end{array}$ \\
\hline
\end{tabular}

When complex particles are emitted instead of individual protons and neutrons the Q-values have to be decreased by the respective binding energies of the compound particles: $\mathrm{np}-\mathrm{d},+2.2 \mathrm{MeV} ; 2 \mathrm{np}-\mathrm{t},+8.48 \mathrm{MeV} ; 2 \mathrm{p} 2 \mathrm{n}-\mathrm{a}, 28.30 \mathrm{MeV}$. **Abundance of isotopes in natural $\mathrm{Yb}(\%):{ }^{168} \mathrm{Yb}-0.13,{ }^{170} \mathrm{Yb}-3.05,{ }^{171} \mathrm{Yb}-14.3,{ }^{172} \mathrm{Yb}-21.9,{ }^{173} \mathrm{Yb}-16.12,{ }^{174} \mathrm{Yb}-31.8,{ }^{176} \mathrm{Yb}-12.7 . * * *$ The Q-values refer to formation of the ground state and were obtained from 14 
Table 3: Measured cross-sections of the ${ }^{\text {nat }} \mathrm{Yb}(\mathrm{d}, \mathrm{xn}){ }^{177,173,172 m g, 171 \mathrm{mg}, 170,169}$ Lu reactions

\begin{tabular}{|c|c|c|c|c|c|c|c|c|c|c|c|c|c|}
\hline \multirow{2}{*}{\multicolumn{2}{|c|}{ Energy $\mathrm{E} \pm \Delta \mathrm{E} \quad(\mathrm{MeV})$}} & \multicolumn{12}{|c|}{ Cross section $\sigma \pm \Delta \sigma(\mathrm{mb})$} \\
\hline & & \multicolumn{2}{|c|}{${ }^{177} \mathrm{Lu}$} & \multicolumn{2}{|c|}{${ }^{173} \mathrm{Lu}$} & \multicolumn{2}{|c|}{${ }^{172 g} \mathrm{Lu}$} & \multicolumn{2}{|c|}{$171 g_{\mathrm{Lu}}$} & \multicolumn{2}{|c|}{${ }^{170} \mathrm{Lu}$} & \multicolumn{2}{|c|}{${ }^{169} \mathrm{Lu}$} \\
\hline 48.2 & 0.3 & & & 233.1 & 26.8 & 210.5 & 23.8 & 347.8 & 39.2 & 324.2 & 37.0 & 274.9 & 27.8 \\
\hline 47.3 & 0.3 & & & 274.9 & 31.8 & 223.4 & 25.2 & 393.9 & 44.4 & 337.8 & 38.5 & 289.6 & 29.3 \\
\hline 45.6 & 0.4 & & & 311.6 & 35.8 & 240.4 & 27.1 & 456.4 & 51.4 & 346.3 & 39.5 & 298.6 & 30.2 \\
\hline 44.7 & 0.4 & & & 303.0 & 34.8 & 231.9 & 26.2 & 476.6 & 53.7 & 323.6 & 37.0 & 285.6 & 28.9 \\
\hline 42.9 & 0.4 & & & 303.7 & 34.8 & 226.0 & 25.5 & 480.9 & 54.1 & 327.2 & 37.3 & 265.9 & 26.9 \\
\hline 42.0 & 0.4 & & & 270.6 & 31.1 & 228.4 & 25.8 & 471.0 & 53.0 & 323.4 & 36.9 & 250.4 & 25.3 \\
\hline 40.1 & 0.5 & & & 259.6 & 30.0 & 232.2 & 26.2 & 442.8 & 49.9 & 342.9 & 39.2 & 221.8 & 22.4 \\
\hline 39.1 & 0.5 & & & 274.2 & 31.8 & 277.3 & 31.2 & 464.2 & 52.2 & 342.6 & 39.0 & 232.9 & 23.6 \\
\hline 37.2 & 0.6 & & & 282.5 & 32.7 & 325.4 & 36.7 & 419.3 & 47.2 & 341.3 & 38.9 & 207.8 & 21.0 \\
\hline 36.1 & 0.6 & & & 275.9 & 31.9 & 345.3 & 38.9 & 408.3 & 46.0 & 328.2 & 37.3 & 187.5 & 19.0 \\
\hline 34.1 & 0.6 & & & 308.0 & 35.3 & 416.4 & 46.9 & 385.8 & 43.5 & 329.7 & 37.6 & 173.8 & 17.6 \\
\hline 32.9 & 0.7 & & & 299.4 & 34.4 & 428.1 & 48.2 & 371.0 & 41.8 & 304.8 & 34.9 & 163.9 & 16.6 \\
\hline 30.7 & 0.7 & & & 312.0 & 35.8 & 420.6 & 47.3 & 367.3 & 41.4 & 268.6 & 30.7 & 136.7 & 13.8 \\
\hline 27.9 & 0.8 & & & 405.4 & 46.3 & 370.5 & 41.7 & 400.5 & 45.1 & 254.6 & 29.1 & 85.6 & 8.7 \\
\hline 25.2 & 0.8 & & & 531.5 & 59.8 & 284.8 & 32.1 & 408.9 & 46.1 & 200.5 & 23.1 & 42.2 & 4.3 \\
\hline 22.3 & 0.9 & & & 547.7 & 62.1 & 245.5 & 27.7 & 310.7 & 35.0 & 165.4 & 19.0 & 25.2 & 2.6 \\
\hline 19.2 & 1.0 & & & 449.3 & 50.8 & 236.9 & 26.7 & 350.6 & 39.5 & 89.3 & 10.7 & 8.3 & 0.9 \\
\hline 13.8 & 1.1 & 239 & 27 & 332.6 & 37.4 & 227.9 & 25.7 & 242.0 & 27.3 & 62.9 & 7.7 & 4.0 & 0.5 \\
\hline 12.9 & 1.1 & 245 & 28 & 108.0 & 12.2 & 71.3 & 8.0 & 52.6 & 5.9 & 9.9 & 1.1 & 0.3 & 0.04 \\
\hline
\end{tabular}

Table 4: Measured cross-sections of the ${ }^{\text {nat }} \mathrm{Yb}(\mathrm{d}, \mathrm{x})^{177,175,169} \mathrm{Yb}$ and ${ }^{\text {nat }} \mathrm{Yb}(\mathrm{d}, \mathrm{x})^{173,168,167,165} \mathrm{Tm}$

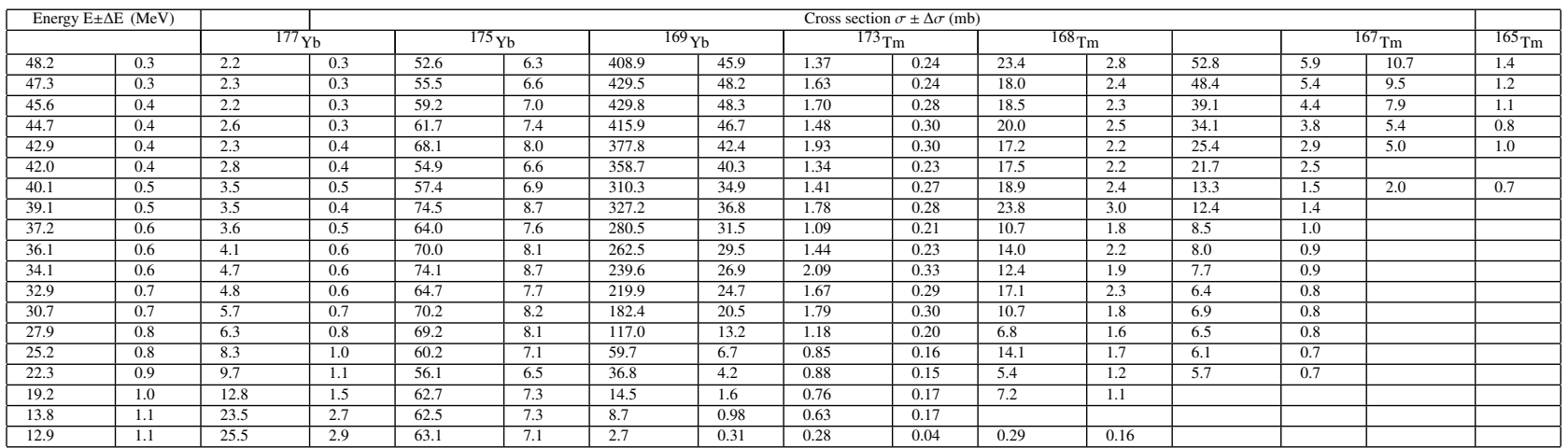

